\title{
Biomechanical comparison of monocortical and bicortical plate fixation for rib fractures in a cadaveric model using a locking plate system
}

\author{
Abby Choke ${ }^{1}$, Yoke Rung Wong ${ }^{2}$, Janna-Vale Joethy ${ }^{1}$ \\ ${ }^{1}$ Department of Plastic, Reconstructive and Aesthetic Surgery, ${ }^{2}$ Biomechanics Laboratory, Singapore General Hospital, Singapore 169856, Singapore \\ Contributions: (I) Conception and design: JV Joethy, A Choke; (II) Administrative support: YR Wong; (III) Provision of study materials or patients: \\ JV Joethy; (IV) Collection and assembly of data: A Choke, YR Wong; (V) Data analysis and interpretation: A Choke, YR Wong; (VI) Manuscript \\ writing: All authors; (VII) Final approval of manuscript: All authors. \\ Correspondence to: Dr. Janna-Vale Joethy. Department of Plastic, Reconstructive and Aesthetic Surgery, Singapore General Hospital, 20 College Road, \\ Singapore 169856, Singapore. Email: janajoethy@hotmail.com.
}

\begin{abstract}
Background: Surgical stabilization of rib fractures is an established form of treatment for complex rib fractures. Plate fixation with bicortical screws placement can cause injury to intra-thoracic organs and pleural irritation from protruding screw tips. The aim of this study is to compare the biomechanical properties of monocortical and bicortical plate fixation for rib fractures using a locking plate system.

Methods: Ten pairs of fresh-frozen cadaveric ribs were harvested. Native ribs were mounted onto a biomechanical tester and statically loaded to failure to induce a rib fracture. The native stiffness of the rib was measured. Next, the ribs were stabilized using the Synthes MatrixRIB (Johnson \& Johnson, USA) locking plate. Left-sided ribs were fixed in a bicortical manner and right-sided ribs were fixed in a monocortical manner. The repaired ribs were subjected to cyclic loading of 50,000 cycles between 2 to $6 \mathrm{~N}$ to simulate physiological respiration, followed by static loading at a rate of $10 \mathrm{~N} / \mathrm{min}$ until failure. The pre and postrepaired stiffness were measured. A high-speed camera was used to record the mechanism of failure.

Results: One left-sided rib was omitted from the study because the fracture occurred at the drill hole site. Left-sided ribs demonstrated a mean native stiffness of $10.0 \mathrm{~N} / \mathrm{mm}$ (SD 3.71) and right-sided $11.92 \mathrm{~N} / \mathrm{mm}$ (SD 3.57). After plate fixation, pre and post cyclic stiffness was $3.32 \mathrm{~N} / \mathrm{mm}$ (SD 1.21) and $4.41 \mathrm{~N} / \mathrm{mm}$ (SD 3.29) for the bicortical group; $3.14 \mathrm{~N} / \mathrm{mm}$ (SD 1.24) and $3.91 \mathrm{~N} / \mathrm{mm}$ (SD 1.98) for the monocortical group. There is no statistical difference found between the two groups $(\mathrm{P}=0.872)$.

Conclusions: Our results show that there is no difference in stability between monocortical and bicortical fixation for rib fractures using a locking plate system. Monocortical fixation is recommended to avoid potential complications.
\end{abstract}

Keywords: Rib fracture; bicortical; monocortical; unicortical; locking plate

Submitted Aug 24, 2019. Accepted for publication Nov 15, 2019.

doi: $10.21037 /$ jtd.2019.12.31

View this article at: http://dx.doi.org/10.21037/jtd.2019.12.31

\section{Introduction}

Rib fractures are a common outcome of thoracic trauma. The severity of fracture may range from a simple isolated rib fracture, to multiple level fractures and flail chest. Traditionally, management of rib fractures was largely conservatively and focused on symptomatic treatment and pain relief. While simple fractures can be managed conservatively, it is well known that patients with multiple rib fractures and the elderly are at a higher risk of adverse outcomes which includes longer hospital stay, longer dependence on mechanical ventilator, and higher risk of developing pneumonia (1). 


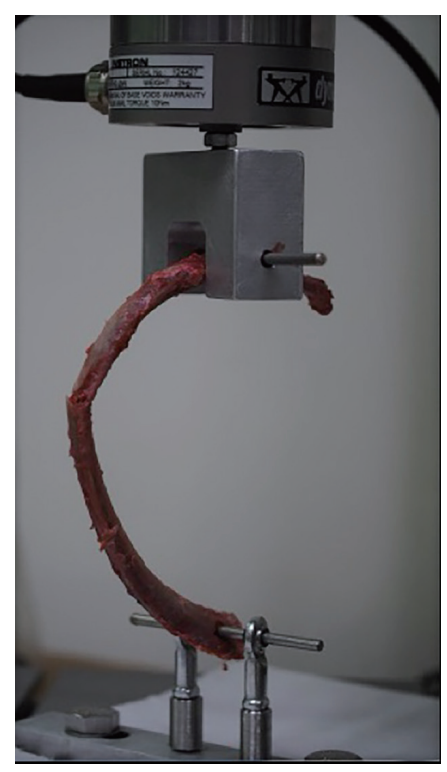

Figure 1 Experimental setup using the Instron E-1000 Dynamic Tester. The rib was statically loaded to failure to induce a clinically realistic fracture pattern.

In 2002, Tanaka et al. randomized 37 patients with flail chest who required mechanical ventilation into two treatment groups: conservative versus surgical fixation. He reported that the group that was treated surgically had a significantly shorter duration on ventilator, shorter duration in intensive care, lower incidence of pneumonia, and improved pulmonary function (2). Several smaller case series also reported reduced mortality, better pain control, better clearance of secretions, and quicker back to work time (3-5).

Different methods of internal fixation have been tried and tested over the years; these included conventional compression plating, intramedullary wires, struts, or absorbable plates. Each of these have their benefits but also had problems like hardware migration, screw pull out, or injury to the neurovascular bundle. In 2010, Bottlang developed a customized implant system based on the human ribs biomechanics and anatomy (6). This implant, known as the Synthes MatrixRIB system (Johnson and Johnson, USA) is a customized titanium rib plating system that adopts the contour of human ribs. These plates are low profile and precontoured, and have a locking mechanism that allows the fractured ribs to be immobilized at a stiffness level optimal for bone healing.

Similar to conventional plating, the locking system recommends screw placement in a bicortical manner. The drilling of both cortices poses a theoretical risk injuring the intra-thoracic organs, and the prominence of the screw tip can result in pleural irritation or pneumothorax. If the screws were aim inferiorly, there is also the possibility of injuring the intercostal neurovascular bundle at the subcostal groove. While there were many comparison studies on screw fixation in long bone fractures, there are no similar studies for rib fractures to date $(7,8)$. The aim of this study is to compare the biomechanical properties of monocortical and bicortical plate fixation for rib fractures using an advanced plating system.

\section{Methods}

This study was conducted in the Biomechanics Laboratory of Singapore General Hospital. Ethics approval from the institution was not a requirement as this was a biomechanical study based on a cadaveric model.

\section{Specimen preparation}

Ten pairs of fresh frozen ribs (Rib 5 to 9) were harvested from two cadavers. Each rib was dissected free from the surrounding soft tissues with careful preservation of the periosteum. All the ribs were stored under $-20{ }^{\circ} \mathrm{C}$ and thawed on the day of experiment. To ensure that all specimens were tested under the same bending load, the ribs were shortened to a consistent arc height of $5 \mathrm{~cm}$. Two $5 \mathrm{~mm}$ drill holes were made at both ends of the rib, one at the rib tubercle and another $15 \mathrm{~mm}$ from the anterior edge of the rib (Figure 1). One of the left-sided rib from the study was omitted because the fracture occurred at the drill hole end rendering it impossible to mount.

\section{Experimental setup}

The specimens were evaluated using the Instron E-1000 Dynamic tester (Instron Corp., USA). A customized jig was fabricated for mounting of the specimens. A $5 \mathrm{~mm}$ diameter metal rod was placed at each end of the ribs through the drill hole, and then mounted on the testing machine. The upper holder of the fixture was attached to the load cell of the tester while the lower holder remained stationary at the tester platform during testing (Figure 1).

\section{Biomechanical test}

The biomechanical tests were designed based on other 

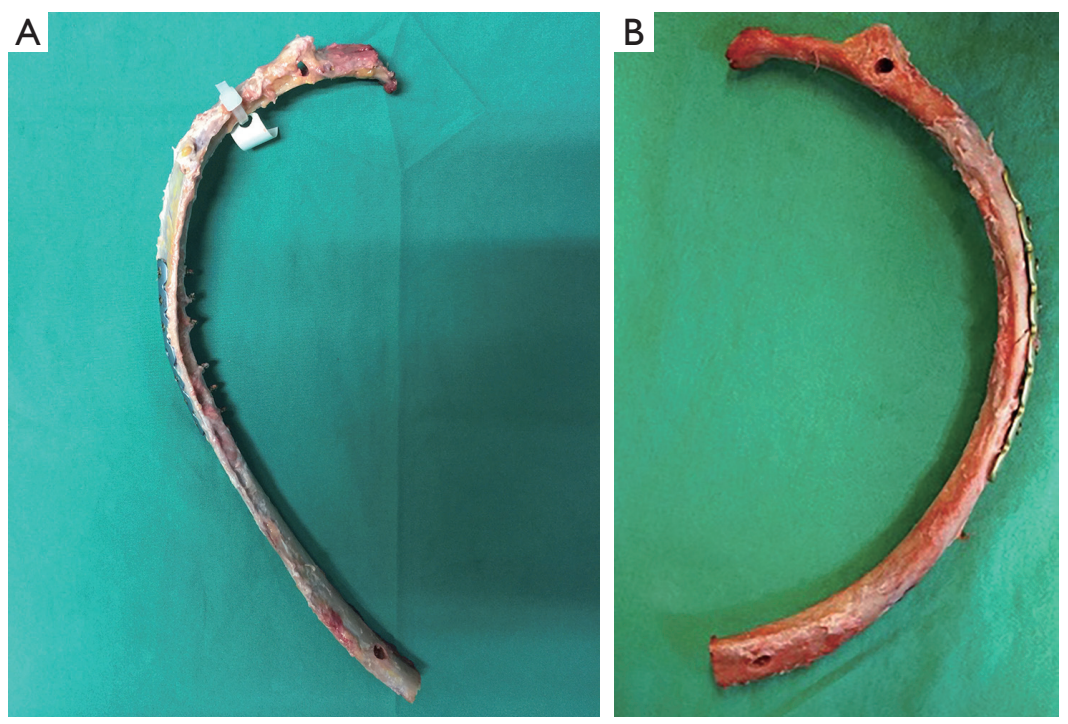

Figure 2 Bicortical and monocortical plate fixation of the rib using the Synthes MatrixRIB plating system. (A) In bicortical fixation, the screw tip traverses both the inner and outer cortices of the rib; (B) the screw tip does not traverse the inner cortex of the rib in monocortical fixation.

biomechanical studies for rib fractures $(6,9)$. The tests comprised of 4 phases:

(I) To determine the native stiffness of the rib;

(i) each rib was statistically loaded at the rate of $10 \mathrm{~N} /$ second to induce a realistic fracture pattern (Figure 1). The native stiffness was measured based on the load displacement curve $(\mathrm{N} / \mathrm{mm})$ produced during the static loading;

(II) Rib fractures repaired using the Synthes MatrixRIB system;

(i) matching plates were chosen based on the side (left or right) and level of the rib (4th to 8th). The plates were shortened to a 7-hole length and carefully bent to match the rib contour;

(ii) the thickness of rib was measured using a caliper to determine the screw length. For left-sided ribs, $2 \mathrm{~mm}$ was added onto the measured rib thickness to achieve a bi-cortical fixation, e.g., a $12 \mathrm{~mm}$ screw for a $10 \mathrm{~mm}$ thickness rib. For right-sided ribs, $2 \mathrm{~mm}$ was deducted e.g., $8 \mathrm{~mm}$ screw for a $10 \mathrm{~mm}$ thick rib to achieve a mono-cortical screw placement (Figure 2A,B);

(iii) the fracture was reduced using a reduction forceps. The plate was placed on the outer cortex of the rib with 3 screw holes positioned on both end of the fracture line;

(iv) the screw length was confirmed using a depth gauge and pre-drilled using a power hand drill with $2.2 \mathrm{~mm}$ drill bit. Then, two screws were placed adjacent to the fracture site to secure the position of the plate. The remaining screws were then placed;

(III) Cyclic loading of plate construct;

(i) the repaired specimen was mounted onto the biomechanical tester and the pre-cyclic stiffness measured. Then, the specimen was subjected to cyclic loading for 50,000 cycles between 2 to $6 \mathrm{~N}$ load (Figure 3) to simulate 48 hours of physiological breathing at 18 breaths per minute (9). After cyclic loading, the stiffness of the specimen was again measured to determine the post-cyclic stiffness;

(IV) Load to failure;

(i) the specimen was subjected to exaggerated static loading until failure. This was used to determine the post-repair construct stiffness;

(ii) a high-resolution camera was used to analyze the mechanism of failure (Figure 4A,B).

Non-parametric Mann-Whitney $U$ test was used for statistical analysis. A P value of less than 0.05 was considered to be statistically significant. 


\section{Results}

Comparison of native and repaired stiffness within and between the method of fixation

As shown in Table 1, the mean native stiffness for left-

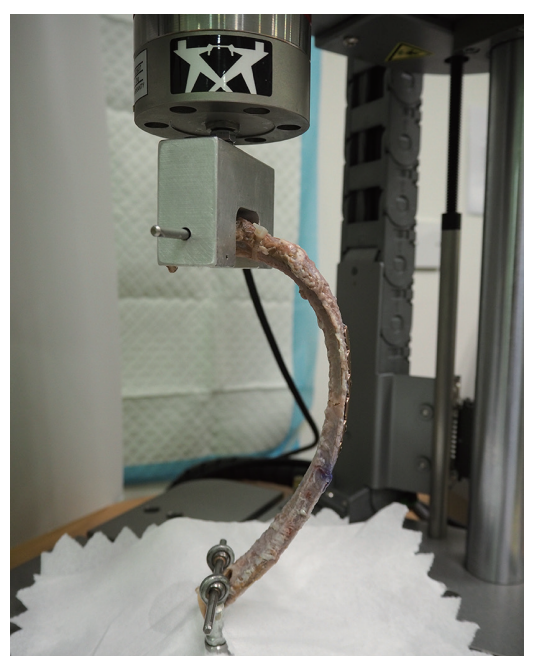

Figure 3 Following plate fixation, the specimen was subjected to cyclical loading for 50,000 cycles at a load of between 2 to 3 Newton. sided and right-sided ribs were $10.03 \mathrm{~N} / \mathrm{mm}$ (SD 3.71) and $11.92 \mathrm{~N} / \mathrm{mm}$ (SD 3.57) respectively. The post repaired stiffness was $3.32 \mathrm{~N} / \mathrm{mm}$ (SD 1.21) for the bicortical group and $3.14 \mathrm{~N} / \mathrm{mm}$ (SD 1.24) for the monocortical group. There is significant difference when comparing the before and after repair stiffness for both groups $(\mathrm{P}<0.001)$. However, no significant difference was found when compared between mono- and bi-cortically repaired ribs $(\mathrm{P}=0.842)$.

\section{Comparison of pre and post cyclic loading stiffness}

As shown in Table 2, the mean pre- and post-cyclic stiffness of bicortical repaired ribs was $3.32 \mathrm{~N} / \mathrm{mm}$ (SD 1.21) and $4.41 \mathrm{~N} / \mathrm{mm}$ (SD 3.29). For the monocortical group, it was $3.14 \mathrm{~N} / \mathrm{mm}$ (SD 1.24) and $3.91 \mathrm{~N} / \mathrm{mm}$ (SD 1.98) (Table 2). No significant difference was found between both groups after cyclic loading $(\mathrm{P}=0.872)$. This indicate that monocortical repaired ribs were not inferior in stiffness compared to the bicortical group.

\section{Mechanism of failure}

The mean load to failure was $76.2 \mathrm{~N}$ (SD 32.4) for the bicortical group and $71.7 \mathrm{~N}$ (SD 32.48) for the monocortical group. We observe that all the specimens in the bicortical
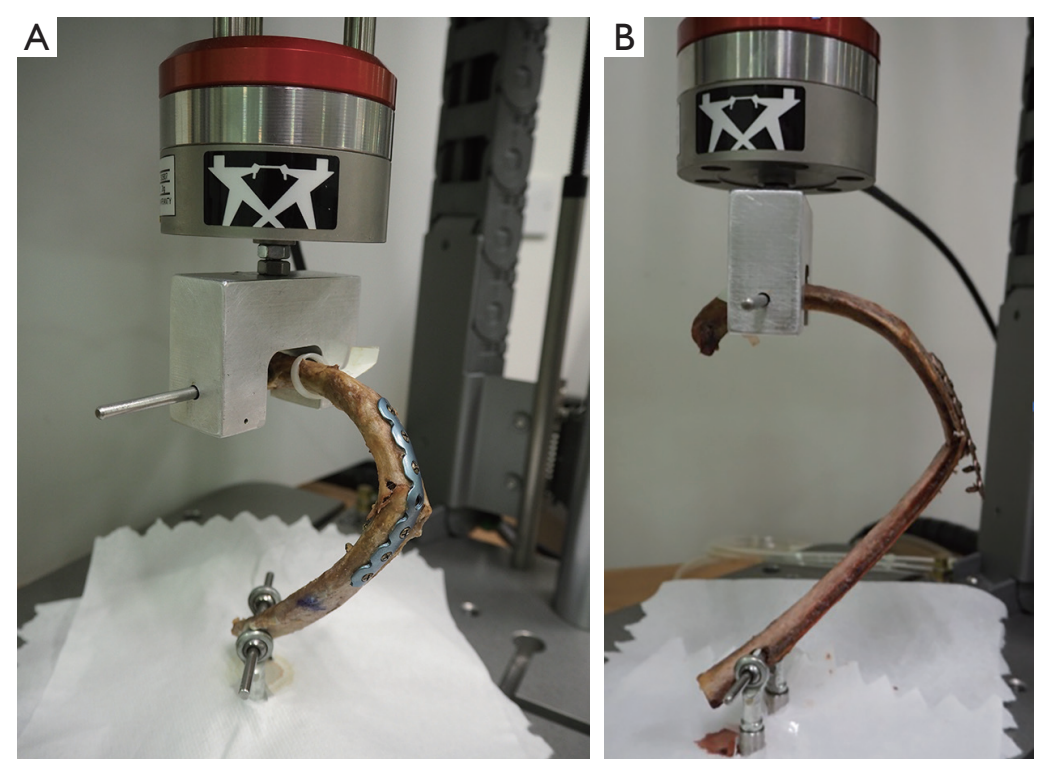

Figure 4 The rib construct was statically loaded to failure at the end of the experiment. The mechanism of failure for this bicortical plating was fracture at the previously fractured site associated with plate bending (A). The monocortical construct in (B) demonstrated screw pullout of the distal portion of the plate. 
Table 1 Comparison between mean native rib stiffness and mean repaired stiffness

\begin{tabular}{lccc}
\hline $\begin{array}{l}\text { Method of } \\
\text { fixation }\end{array}$ & $\begin{array}{c}\text { Mean native } \\
\text { stiffness (N/mm) }\end{array}$ & $\begin{array}{c}\text { Mean repaired } \\
\text { stiffness (N/mm) }\end{array}$ & P value \\
\hline Bicortical $(\mathrm{n}=9)$ & $10.03(\mathrm{SD} 3.71)$ & $3.32(\mathrm{SD} 1.21)$ & $<0.001$ \\
Monocortical $(\mathrm{n}=10)$ & $11.92(\mathrm{SD} 3.57)$ & $3.14(\mathrm{SD} 1.24)$ & $<0.001$ \\
$\mathrm{P}$ (Mann & & $\begin{array}{l}0.842, \text { not significant } \\
\text { Whitney test) }\end{array}$ & between both groups \\
\hline
\end{tabular}

Table 2 Comparison between pre- and post-cyclic stiffness of the two groups

\begin{tabular}{lccc}
\hline $\begin{array}{l}\text { Method of } \\
\text { fixation }\end{array}$ & $\begin{array}{c}\text { Pre-cyclic } \\
\text { stiffness (N/mm) }\end{array}$ & $\begin{array}{c}\text { Post-cyclic } \\
\text { stiffness (N/mm) }\end{array}$ & P value \\
\hline Bicortical ( $\mathrm{n}=9)$ & $3.32(\mathrm{SD} 1.21)$ & $4.41(\mathrm{SD} 3.29)$ & 0.878 \\
Monocortical ( $\mathrm{n}=10)$ & $3.14(\mathrm{SD} 1.24)$ & $3.91(\mathrm{SD} 1.98)$ & 0.579 \\
$\mathrm{P}$ (Mann & & $\begin{array}{l}0.872, \text { not significant } \\
\text { Whitney test) }\end{array}$ & \multicolumn{2}{l}{ between both groups } \\
\hline
\end{tabular}

Table 3 Comparison of load to failure $(\mathrm{N})$ and mechanism of failure

\begin{tabular}{lccc}
\hline Failure mode & Bicortical & Monocortical & $P$ \\
\hline $\begin{array}{l}\text { Mean load to } \\
\text { failure }(\mathrm{N})\end{array}$ & $76.2(\mathrm{SD} 32.4)$ & $71.7(\mathrm{SD} 32.48)$ & $\begin{array}{c}\mathrm{P}=0.549, \mathrm{not} \\
\text { significant }\end{array}$ \\
Mechanism & & & \\
Plate bending & $9(100 \%)$ & $8(80 \%)$ \\
Screw pull out & $0(0 \%)$ & $2(20 \%)$ \\
\hline
\end{tabular}

group ( $n=9)$ failed by plate bending and re-fracture at the previously fractured site. The same mechanism was seen in 8 out of 10 specimens in the monocortical group, with the other 2 specimens demonstrating screw pull out (Table 3).

\section{Discussion}

There are several indications for surgical fixation of rib fractures including multiple rib fractures, chronic painful rib fractures, non-union deformity, and flail chest (10). An ideal fracture fixation should have satisfactory reduction of fracture, provide sufficient stability for bone healing, sufficient blood supply and soft tissue, as well as allow early mobilization. This task is challenging because of the unique anatomy of the human ribs. Compression plating with bicortical screws placement is a traditional technique well described in literature $(4,5)$. These conventional plates are high profile and exceed the stiffness of human ribs, making it prone for failure by screw pullout. Moreover, in the setting of an emerging elderly population who suffers from osteoporosis, these highly rigid implants can cause chronic pain and peri-prosthetic fracture (11). The introduction of a low-profile titanium locking plate system addressed many problems of a conventional plate. The locking design distributes the stress along the length of the plate without the need for compression of the bone, allowing it to preserve the periosteal blood supply (12). The thinner precontoured plates also allow better conformation onto the curvature of the rib and reduce the need for intra-operative bending of plates.

With an increasing number of operative fixations, hardware related problems are also anticipated. The intimate anatomy of the underlying thoracic organs and great vessels are at risk. The drilling of both cortices risks injury to the intra-thoracic organs, ranging from lung parenchymal injury to fatal cardiac injury (13). The prominence of the screw tip may result in pleural irritation or pneumothorax. Technical caution is imperative during placement of screws. If plating can be performed in a monocortical fixation, we can minimize the complications related to bicortical fixation.

Not surprisingly, our data suggested that bicortical fixation demonstrated a higher stiffness than monocortical fixation. This can be attributed to the greater number of cortices the screw engages in a bicortical fixation (12 cortices for 6 screws). However, this property is less relevant in human ribs as stress loading in human ribs is not axially directed and does not involve weight bearing. This is in contrast to other long bones where a rigid construct is required to withstand axial loading. The greater number of cortices the screw engages can also weaken the bone, making it a potential site for periprosthetic fracture.

This study has several limitations. Firstly, this study focused on the testing of individual rib, whereas in reality the chest wall moves in tandem with the diaphragm, sternum and chest wall musculature. This study is also limited to the single method of axial compressive loading and did not account for the torsional force that occurs in physiological breathing. The induced fracture also may not accurately represent the in-vivo behavior of rib fractures which in reality could be more complex and compounded by other injuries.

In summary, our results demonstrated no significant 
difference in the construct stiffness between monocortical and bicortical screw fixation. This suggested that monocortical plate fixation can provide similar stability as a bicortical fixation, and represents a reasonable option to avoid complication associated with bicortical screw. However, it remains unclear whether these differences will be clinically significant. We hope to expand future study to include rotational forces. We believe that with this understanding, modification can be made intra-operatively to reduce the risk of injury caused by the screws, or combine the use of both monocortical and bicortical screw for a locking plate.

\section{Acknowledgments}

Funding: This work was supported by the SingHealth Surgery Academic Clinical Program (ACP) Seed Grant [GRDUKS002301].

\section{Footnote}

Conflicts of Interest: The authors have no conflicts of interest to declare.

Ethical Statement: The authors are accountable for all aspects of the work in ensuring that questions related to the accuracy or integrity of any part of the work are appropriately investigated and resolved. Ethics approval from the institution was not a requirement as this was a biomechanical study based on a cadaveric model.

\section{References}

1. Holcomb JB, McMullin NR, Kozar RA, et al. Morbidity from rib fractures increases after age 45. J Am Coll Surg 2003;196:549-55.

2. Tanaka H, Yukioka T, Yamaguti Y, et al. Surgical Stabilization of Internal Pneumatic Stabilization. A

Cite this article as: Choke A, Wong YR, Joethy JV. Biomechanical comparison of monocortical and bicortical plate fixation for rib fractures in a cadaveric model using a locking plate system. J Thorac Dis 2019;11(12):4966-4971. doi: 10.21037/jtd.2019.12.31
Prospective Randomized Study of Management of Severe Flail Chest Patients. J Trauma 2002;52:727-32; discussion 732.

3. Ahmed Z, Mohyuddin Z. Management of flail chest injury: internal fixation versus endotracheal intubation and ventilation. J Thorac Cardiovasc Surg 1995;110:1676-80.

4. Engel C, Krieg JC, Madey SM, et al. Operative chest wall fixation with osteosynthesis plates. J Trauma 2005;58:181-6.

5. Lardinois D, Krueger T, Dusmet M, et al. Pulmonary function testing after operative stabilisation of the chest wall for flail chest. Eur J Cardiothorac Surg 2001;20:496-501.

6. Bottlang M, Walleser S, Noll M, et al. Biomechanical rationale and evaluation of an implant system for rib fracture fixation. Eur J Trauma Emerg Surg 2010;36:417-26.

7. Pater TJ, Grindel SI, Schmeling GJ, et al. Stability of unicortical locked fixation versus bicortical non-locked fixation for forearm fractures. Bone Res 2014;2:14014.

8. Doht S, Meffert RH, Raschke MJ, et al. Biomechanical analysis of the efficacy of locking plates during cyclic loading in metacarpal fractures. ScientificWorldJournal 2014;2014:648787.

9. Sales JR, Ellis T, Mayberry JC, et al. Biomechanical testing of a novel, minimally invasive rib fracture plating system. J Trauma 2008;64:1270-4.

10. Cacchione RN, Richardson JD, Seligson D. Painful nonunion of multiple rib fractures managed by operative stabilization. J Trauma 2000;48:319-21.

11. Hellberg K, de Vivie ER, Fuchs K, et al. Stabilization of flail chest by compression osteosynthesis - experimental and clinical results. Thorac Cardiovasc Surg 1981;29:275-81.

12. Cronier P, Pietu G, Dujardin C, Bigorre N, Ducellier F, Gerard R. The concept of locking plates. Orthop Traumatol Surg Res 2010. [Epub ahead of print].

13. Pieracci FM, Johnson JL, Stovall RT, et al. Completely thoracoscopic, intra-pleural reduction and fixation of severe rib fractures. Trauma Case Rep 2015;1:39-43. 